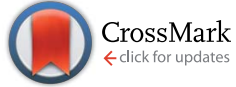

Cite this: RSC Adv., 2017, 7, 1606

Received 20th October 2016

DOI: 10.1039/c6ra25567a

www.rsc.org/advances Accepted 7th December 2016

\section{Tuning the optical and electrochemical properties of conjugated all-thiophene dendrimers via core functionalization with a benzothiadiazole unit $\uparrow$}

\author{
Wei Gao, ${ }^{\text {ad }}$ Junkai Wang, ${ }^{\mathrm{b}}$ Qun Luo, ${ }^{a}$ Yi Lin, ${ }^{\mathrm{C}}$ Yuchao Ma, ${ }^{a}$ Junyan Dou, ${ }^{a}$ \\ Hongwei Tan, ${ }^{* b}$ Chang-Qi Ma*a and Zheng Cui*a
}

\begin{abstract}
Three-dimensional (3D) $\pi$-conjugated dendrimers are a new class of structurally defined macromolecules for use in organic electronics. Herein, a new family of dendritic oligothiophenes (DOT-C-BTs) up to the $2^{\text {nd }}$ generation with benzothiadiazole (BT) groups at the core have been synthesized by a precise convergent approach. The well-defined chemical structures and the monodispersed nature of these DOT-C-BTs were fully confirmed by NMR spectroscopy, MALDI-TOF mass spectrometry (MALDI-TOF MS), highresolution mass spectrometry (HR MS), and gel-permeation chromatography (GPC) measurements. The optical and electrochemical properties were investigated by UV-vis absorption, and cyclic voltammetry. The insertion of electron-deficient benzothiadiazole (BT) groups into the core of the conjugated dendritic oligothiophenes resulted in a large redshift compared to all-thiophene dendrimers. Cyclic voltammetry measurements showed one reversible reduction process and multiple oxidation waves for these functionalized dendritic oligothiophenes, due to the reduction of the BT core and the oxidation of different $\pi$-conjugated chains, respectively. Applications of DOT-c-BTs in organic solar cells as the electron donor were presented. However, unfavorable nanophase separation in the blended film led to poor device performance.
\end{abstract}

\section{Introduction}

Due to their outstanding optical, redox, self-assembling, chargetransport properties and excellent chemical stability, onedimensional linear oligo- and polythiophenes are among the best investigated and most frequently used organic semiconductor materials in organic electronics, ${ }^{\mathbf{1}}$ including organic solar cells (OSCs), ${ }^{2}$ organic field-effect transistors (OFETs), ${ }^{3}$ organic light-emitting transistors, ${ }^{4}$ and organic light-emitting diodes (OLEDs). ${ }^{5}$ On the other hand, thiophene-based materials with higher molecular dimensionality, such as 2D cyclicshaped, ${ }^{6}$ X-shaped, ${ }^{7}$ star-shaped ${ }^{8}$ as well as dendritic structur$\mathrm{es}^{2 a, 9}$ have been reported for use in organic electronics.

Conjugated dendrimers are typically three-dimensional (3D) hyperbranched shape-persistent macromolecules with high molecular weights, well-defined and monodisperse chemical

\footnotetext{
${ }^{a}$ Printable Electronics Research Center, Suzhou Institute of Nano-Tech and Nano-Bionics, Chinese Academy of Sciences, 398 Ruoshui Road, SEID SIP, Suzhou, Jiangsu 215123, PR China. E-mail: cqma2011@sinano.ac.cn; zcui2009@sinano.ac.cn ${ }^{b}$ College of Chemistry, Beijing Normal University, No. 19, XinjieKouWai St., HaiDian District, Beijing, 100875, P. R. China.E-mail: hongwei.tan@bnu.edu.cn

${ }^{c}$ Department of Chemistry, Xi'an Jiaotong Liverpool University, 111 Ren Ai Road, SEID SIP, Suzhou, 215123, P. R. China

${ }^{d}$ University of Chinese Academy of Sciences, Beijing, 100049, P. R. China

$\dagger$ Electronic supplementary information (ESI) available. See DOI: 10.1039/c6ra25567a
}

structures that are highly controllable due to precise synthetic approaches. ${ }^{2 a, 10}$ Therefore, conjugated dendrimers combine well-defined chemical structure of oligomers. ${ }^{11}$ Whereas polymers are prone to suffer batch-to-batch variations due to their polydispersity of molecular weights and end-group effects, ${ }^{\mathbf{1 2}}$ conjugated dendrimers are believed to have better reproducibility owing to their well-defined and monodispersed chemical structures. $^{13}$ In addition, conjugated dendrimers are also considered as model compounds for elucidating structureproperty relationship of conductive polymers, which could serve as important guideline for the molecule structure modification and optimization for developing high performance organic electronic materials. ${ }^{\mathbf{1 4}}$

So far, various conjugated dendrimers based on different branching blocks have been developed, ${ }^{15}$ such as benzene, ${ }^{\mathbf{1 6}}$ phenylene ethynylene, ${ }^{17}$ truxene, ${ }^{18}$ carbazole, ${ }^{19}$ and thiophene. ${ }^{9 b, 20}$ Dendritic oligothiophenes (DOTs) are among the most representative organic electronic materials owing to their unique optical and electronic properties. All-thiophene dendrons and dendrimers were synthesized up to a fourth generation by a convergent/divergent approach in 2007, which contains 90 thiophene units in one molecule. ${ }^{21}$ To increase the functionalities of the thiophene dendrimers, various functional groups, including electron push-pull moiety, ${ }^{14 b, 22}$ dye moiety, ${ }^{23}$ bioactive groups ${ }^{24}$ have been are introduced to the core,,$^{22 a-f, 23 c-e, 25}$ the advantages of high molecular weight of polymers and 
the branching $\pi$-bridge, ${ }^{14 b, 22 g, 25 d}$ and the periphery ${ }^{22-i, 24,26}$ of dendritic oligothiophenes molecules, demonstrating that DOTs are versatile building blocks for constructing 3D conjugated molecules.

As for the application of these thiophene dendrimers in organic solar cells, Ma et al. first reported that power conversion efficiency (PCE) up to $1.65 \%$ was achieved for DOT:PC ${ }_{61} \mathrm{BM}$ ([6,6]-phenyl- $\mathrm{C}_{61}$-butyric acid methyl ester) solar cells, ${ }^{14 a}$ which was further improved to $3.5 \%$ when using $\mathrm{PC}_{71} \mathrm{BM}$ as the electron acceptor. ${ }^{27}$ For their all-thiophene structure, the absorption maxima of DOTs are localized at $420-450 \mathrm{~nm}$, which is far from ideal for organic solar cell application. Functionalization of DOTs to improve the light absorption ability by introducing metal complex, ${ }^{23 e, 25 a, 28}$ squaraine dye, ${ }^{23 c}$ or electron accepting pyrazino[2,3-g]quinoxaline unit ${ }^{22 c}$ on the core, or introducing intramolecular donor- $\pi$-acceptor $(\mathrm{D}-\pi-\mathrm{A})$ structures $^{22 h, 23 f}$ were performed. Smaller optical band gaps and broader light absorption spectra were achieved for these materials. However, device performances of these thiophene dendrimer based materials are not satisfied yet.

Benzothiadiazole (BT) was recently proved to be one of the most effective building blocks for the synthesis of organic semiconducting materials, especially for use in organic solar cells. $^{29}$ It possesses excellent optoelectronic characteristics, such as strong electron-withdrawing nature, intensive light absorption ability, highly conjugated and coplanar structure, and good photochemical stability. ${ }^{30}$ Till now, a number of narrow band gap BT-based copolymers, ${ }^{31}$ and small molecules ${ }^{32}$ show high PCEs in BHJSCs. Herein, we present the synthesis of a new class of BT-core conjugated thiophene dendrimers (DOTc-BT). The chemical structures of these molecules were proved by NMR spectroscopic, MALDI-TOF mass-spectrometric, and HR MS. MALDI-TOF mass-spectrometric and GPC analysis clearly showed the defined and monodisperse structure of these compounds. The optical and electrochemical properties of these compounds were also investigated in detail. In addition, their photovoltaic performance in BHJSCs with fullerene electron acceptor $\mathrm{PC}_{61} \mathrm{BM}$ is presented.

\section{Experimental}

\subsection{Materials}

Chemicals were purchased and used without further purification: BT-Br ${ }_{2}$ (Puyang Huicheng Electronic Material Co., Ltd), $\mathrm{Pd}_{2}(\mathrm{dba})_{3} \cdot \mathrm{CHCl}_{3} \quad$ (Sigma-Aldrich), $\mathrm{HP}(t-\mathrm{Bu})_{3} \cdot \mathrm{BF}_{4} \quad$ (SigmaAldrich), TBAF (Energy Chemical), $\mathrm{K}_{2} \mathrm{CO}_{3}$ (Enox®). Solvents were purified and dried by usual methods prior to use and typically used under inert gas atmosphere. ${ }^{33}$

\subsection{Instruments and measurements}

Nuclear magnetic resonance (NMR) spectra were recorded on a Bruker Avance III 400 spectrometer $\left({ }^{1} \mathrm{H}\right.$ NMR: $400 \mathrm{MHz},{ }^{13} \mathrm{C}$ NMR: $100 \mathrm{MHz}$ ). Chemical shifts are denoted in $\delta(\mathrm{ppm})$, and were referenced to tetramethylsilane (TMS) via the residual nondeuterated solvent peaks ( $\mathrm{CDCl}_{3}:{ }^{1} \mathrm{H}$ NMR: $7.26 \mathrm{ppm},{ }^{13} \mathrm{C}$ NMR: $77.0 \mathrm{ppm} ; \mathrm{C}_{2} \mathrm{D}_{2} \mathrm{Cl}_{4}:{ }^{1} \mathrm{H}$ NMR: $6.00 \mathrm{ppm},{ }^{13} \mathrm{C}$ NMR: $74.0 \mathrm{ppm}$ ) as internal standard. The splitting patterns are designated as follows: singlet (s), doublet (d), triplet (t), and multiplet (m). Matrix assisted laser desorption/ionization time-of-flight mass spectrometry (MALDI-TOF MS) were performed on a Bruker Autoflex Speed using trans-2-[3-(4-tert-butylphenyl)-2-methyl-2propenylidene]malononitrile (DCTB) as the matrix. High resolution mass spectrometry (HRMS) was performed on a Bruker ultraflextreme MALDI-TOF/TOF (operation mode: MALDI; matrix: DCTB). Gel Permeation Chromatography (GPC) measurement was performed on a Waters Breeze separations module apparatus with THF as the eluent (flow rate $1 \mathrm{~mL}$ $\left.\min ^{-1}, 35{ }^{\circ} \mathrm{C}\right)$. Number-average molecular weight $\left(M_{\mathrm{n}}\right)$ and polydispersity index $\left(M_{\mathrm{w}} / M_{\mathrm{n}}\right)$ of compounds were determined by GPC analysis relative to polystyrene standards. UV-vis absorption spectra of these new materials in chloroform $\left(\mathrm{CHCl}_{3}\right)$ solution and thin film were recorded on a Perkin Elmer Lambda 750 UV-vis Spectrophotometer. For UV-vis absorption spectrum measurement in solution, three concentrated solutions (around $10^{-4} \mathrm{~mol} \mathrm{~L}^{-1}$ ) were prepared independently, each of which were further diluted to get three diluted solutions (with concentration around $10^{-7}$ to $10^{-6} \mathrm{~mol} \mathrm{~L}^{-1}$ ) for UV-vis absorption measurement. The absorption spectra of the dilute solutions were recorded, and the data points of the absorbance at a certain wavelength $v s$. concentration were then plotted. A good linear relationship was found for all these compounds, suggesting no obvious intermolecular interaction was found in such a concentration range. The molecular molar extinction coefficient $(\varepsilon)$ was obtained from the slope of the best-fit line over the above mentioned data points according to the BeerLambert's law equation, $A=\varepsilon L c$. Thin film samples for UV-vis spectra measurement were prepared by spin-casting a chloroform solution on quartz glasses. The photoluminescence (PL) spectra of the DOT-c-BTs in chloroform solution were obtained with an F-4600 fluorescence spectrophotometer.

Cyclic voltammetry (CV) experiments were performed with a RST-3000 Electrochemistry Workstation (Suzhou Risetech Instrument Co., Ltd). All CV measurements were carried out at room temperature with a conventional three-electrode configuration under nitrogen atmosphere. The electrochemical cyclic voltammetry was performed in a $0.1 \mathrm{M}$ tetrabutylammonium hexafluorophosphate $\left(\mathrm{TBAPF}_{6}\right) /$ dichloromethane (DCM) solution with a scan speed of $100 \mathrm{mV} \mathrm{s}^{-1}$. A Pt disk $(\phi=1 \mathrm{~mm})$ embedded in Teflon was used as the working electrode. The surface was polished before use. A Pt sheet $\left(\sim 1 \mathrm{~cm}^{2}\right)$ and $\mathrm{Ag} / \mathrm{AgCl}$ were used as the counter and reference electrodes, respectively. After the measurement, small amount of ferrocene was added in the solution and the ferrocene/ferrocenium $\left(\mathrm{Fc} / \mathrm{Fc}^{+}\right)$redox couple was measured as an internal standard. Transmission electron microscopy (TEM) tests were performed on a Tecnai G2 F20 S-Twin $200 \mathrm{kV}$ field-emission electron microscope (FEI). Specimens for the TEM experiments were obtained by transferring the floated blend films from the water onto the 200 mesh copper grid.

\subsection{Synthesis}

6T-c-BT-Si. Compound 4,7-dibromobenzo[c]-1,2,5thiadiazole $\left(\mathbf{B T}^{-B_{2}}\right)(240 \mathrm{mg}, 822 \mu \mathrm{mol})$, B-3T-Si $(1.05 \mathrm{~g}, 2.02$ 
$\mathrm{mmol}),\left[\mathrm{Pd}_{2}(\mathrm{dba})_{3}\right] \cdot \mathrm{CHCl}_{3}(34 \mathrm{mg}, 33 \mu \mathrm{mol})$, and $\mathrm{HP}(t \mathrm{Bu})_{3} \cdot \mathrm{BF}_{4}$ (20 mg, $67 \mu \mathrm{mol}$ ) were dissolved into well-degassed THF $(100 \mathrm{~mL})$. The reaction mixture was bubbled with argon and a well-degassed aqueous solution of $\mathrm{K}_{2} \mathrm{CO}_{3}(1.0 \mathrm{M}, 8.0 \mathrm{~mL}, 8.0$ $\mathrm{mmol}$ ) was added dropwise. The reaction mixture was stirred overnight at room temperature and then poured into water $(150 \mathrm{~mL})$ with some drops of $2 \mathrm{M} \mathrm{HCl}$. The organic layer was separated and the aqueous layer was extracted with $\mathrm{CH}_{2} \mathrm{Cl}_{2}$. The combined organic extracts were dried over $\mathrm{Na}_{2} \mathrm{SO}_{4}$. The solvent was removed by rotary evaporation to give residue. The residue was purified by column chromatography on silica gel eluting with hexane/dichloromethane $(5: 1)$ to give the product (650 mg, 87\%). ${ }^{1} \mathrm{H} \mathrm{NMR}\left(\mathrm{CDCl}_{3}, 400 \mathrm{MHz}\right): \delta=8.18(\mathrm{~s} ; 2 \mathrm{H}), 7.88$ (s; $2 \mathrm{H}), 7.25$ (d, $J=3.44 \mathrm{~Hz} ; 2 \mathrm{H}), 7.21$ (d, $J=3.36 \mathrm{~Hz} ; 2 \mathrm{H}), 7.18$ (d, $J=3.40 \mathrm{~Hz} ; 2 \mathrm{H}), 7.15$ (d, $J=3.44 \mathrm{~Hz} ; 2 \mathrm{H}), 0.345$ (s; 18H), $0.323 \mathrm{ppm}(\mathrm{s} ; 18 \mathrm{H}) .{ }^{13} \mathrm{C} \mathrm{NMR}\left(\mathrm{CDCl}_{3}, 100 \mathrm{MHz}\right): \delta=152.35$, 142.51, 142.21, 140.83, 140.14, 137.16, 134.24, 133.52, 132.31, 130.50, 128.58, 128.05, 125.28, 125.17, -0.007, -0.099; MALDITOF MS: $m / z$ calcd for $\mathrm{C}_{42} \mathrm{H}_{48} \mathrm{~N}_{2} \mathrm{~S}_{7} \mathrm{Si}_{4}$ (matrix: DCTB): 916.1, found: 916.3 ; HRMS: $\mathrm{m} / z$ calcd for $\mathrm{C}_{42} \mathrm{H}_{48} \mathrm{~N}_{2} \mathrm{~S}_{7} \mathrm{Si}_{4}$ : 916.0940; found: 916.0958 .

6T-c-BT-H. TBAF (340 mg, $1.3 \mathrm{mmol}$ ) and 6T-c-BT-Si (200 mg, $218 \mu \mathrm{mol})$ dissolved in THF $(5.0 \mathrm{~mL})$ at room temperature. The reaction mixture was stirred at this temperature for $10 \mathrm{~min}$, and then was precipitated in $30 \mathrm{~mL}$ cooled methanol. The solid was filtrated, washed with methanol, to yield residue as a dark-red solid. The residue was purified by column chromatography on silica gel eluting with hexane/dichloromethane $(4: 1)$ to give the product (123 mg, 90\%). ${ }^{1} \mathrm{H} \mathrm{NMR}\left(\mathrm{CDCl}_{3}, 400 \mathrm{MHz}\right): \delta=8.16$ (s; $2 \mathrm{H}), 7.87(\mathrm{~s} ; 2 \mathrm{H}), 7.34-7.35\left(\mathrm{dd}, J_{1}=1.20 \mathrm{~Hz}, J_{2}=3.24 \mathrm{~Hz} ; 2 \mathrm{H}\right)$, $7.33-7.34\left(\mathrm{dd}, J_{1}=1.20 \mathrm{~Hz}, J_{2}=3.32 \mathrm{~Hz} ; 2 \mathrm{H}\right), 7.22-7.23\left(\mathrm{dd}, J_{1}=\right.$ $\left.1.16 \mathrm{~Hz}, J_{2}=3.60 \mathrm{~Hz} ; 2 \mathrm{H}\right), 7.16-7.17\left(\mathrm{dd}, J_{1}=1.20 \mathrm{~Hz}, J_{2}=3.56\right.$ $\mathrm{Hz} ; 2 \mathrm{H}), 7.03-7.08(\mathrm{~m} ; 4 \mathrm{H}) .{ }^{13} \mathrm{C} \mathrm{NMR}\left(\mathrm{C}_{2} \mathrm{D}_{2} \mathrm{Cl}_{4}, 100 \mathrm{MHz}\right): \delta=$ 152.42, 137.31, 137.14, 134.85, 133.63, 132.59, 130.37, 127.80, 127.31, 127.22, 127.03, 126.94, 125.82, 125.38, 125.35; MALDITOF MS: $m / z$ calcd for $\mathrm{C}_{30} \mathrm{H}_{16} \mathrm{~N}_{2} \mathrm{~S}_{7}$ (matrix: DCTB): 627.9, found: 628.1 ; HRMS: $m / z$ calcd for $\mathrm{C}_{30} \mathrm{H}_{16} \mathrm{~N}_{2} \mathrm{~S}_{7}$ : 627.9358; found: 627.9374 .

18T-c-BT-Si. Compound 4,7-dibromobenzo[c]-1,2,5thiadiazole BT-Br 2 (75 mg, $257 \mu \mathrm{mol})$, B-9T-Si $(710 \mathrm{mg}, 615$ $\mu \mathrm{mol}),\left[\mathrm{Pd}_{2}(\mathrm{dba})_{3}\right] \cdot \mathrm{CHCl}_{3}(10 \mathrm{mg}, 10 \mu \mathrm{mol})$, and $\mathrm{HP}(t \mathrm{Bu})_{3} \cdot \mathrm{BF}_{4}$ $(6 \mathrm{mg}, 20 \mu \mathrm{mol})$ were dissolved into well-degassed THF $(50 \mathrm{~mL})$. The reaction mixture was bubbled with argon and a welldegassed aqueous solution of $\mathrm{K}_{2} \mathrm{CO}_{3}(1.0 \mathrm{M}, 4.0 \mathrm{~mL}, 4.0$ $\mathrm{mmol}$ ) was added dropwise. The reaction mixture was stirred overnight at room temperature, concentrated to $10 \mathrm{~mL}$ and then poured into water $(50 \mathrm{~mL})$ with some drops of $2 \mathrm{M} \mathrm{HCl}$. The mixture was extracted with $\mathrm{CH}_{2} \mathrm{Cl}_{2}$. The combined organic extracts dried over $\mathrm{Na}_{2} \mathrm{SO}_{4}$. The solvent was removed by rotary evaporation. The residue was filtered through a short column of silica gel to remove any inorganic salts. The filtrate was concentrated and purified by SEC column chromatography eluting with THF to give the product (450 mg, 80\%). ${ }^{1} \mathrm{H}$ NMR $\left(\mathrm{CDCl}_{3}, 400 \mathrm{MHz}\right): \delta=8.17(\mathrm{~s} ; 2 \mathrm{H}), 7.88(\mathrm{~s} ; 2 \mathrm{H}), 7.24(\mathrm{~s} ; 2 \mathrm{H}), 7.21$ (s; 2H), 7.18 (d, $J=3.80 \mathrm{~Hz} ; 2 \mathrm{H}), 7.10-7.17$ (m; 22H), 0.30$0.31 \mathrm{ppm}(\mathrm{m} ; 72 \mathrm{H}) .{ }^{13} \mathrm{C} \mathrm{NMR}\left(\mathrm{CDCl}_{3}, 100 \mathrm{MHz}\right): \delta=152.12$, 142.26, 142.14, 141.98, 141.90, 140.76, 140.69, 140.00, 139.90,
137.72, 137.56, 136.88, 136.23, 135.39, 135.03, 134.15, 133.89, 133.12 , 132.20, 132.17, 131.74, 130.85, 130.53, 130.26, 128.56, 128.53, 128.46, 127.97, 127.93, 126.66, 126.45, 125.05, 124.88, 124.16, 124.14; MALDI-TOF MS: $m / z$ calcd for $\mathrm{C}_{102} \mathrm{H}_{104} \mathrm{~N}_{2} \mathrm{~S}_{19} \mathrm{Si}_{8}$ (matrix: DCTB): 2188.1, found: 2188.6; HRMS: $\mathrm{m} / \mathrm{z}$ calcd for $\mathrm{C}_{102} \mathrm{H}_{104} \mathrm{~N}_{2} \mathrm{~S}_{19} \mathrm{Si}_{8}$ : 2188.1047; found: 2188.1068 .

18T-c-BT-H. TBAF (442 mg, $1.69 \mathrm{mmol}$ ) and 18T-c-BT-Si (180 mg, $82.3 \mu \mathrm{mol})$ dissolved in THF $(5.0 \mathrm{~mL})$ at room temperature. The reaction mixture was stirred at this temperature for $10 \mathrm{~min}$, and then was precipitated in $30.0 \mathrm{~mL}$ cooled methanol. The solid was filtrated, washed with methanol, to give the residue as a brown solid. The residue was purified by column chromatography and SEC (113 mg, 85\%). ${ }^{1} \mathrm{H}$ NMR $\left(\mathrm{CDCl}_{3}, 400 \mathrm{MHz}\right): \delta=8.17(\mathrm{~s} ; 2 \mathrm{H}), 7.90(\mathrm{~s} ; 2 \mathrm{H}), 7.32-7.34(\mathrm{~m}$; $8 \mathrm{H}), 7.26$ (s; 2H), 7.15-7.23 (m; 14H), 7.10-7.12 (m; 4H), 7.035$7.042(\mathrm{~m} ; 8 \mathrm{H}) .{ }^{13} \mathrm{C} \mathrm{NMR}\left(\mathrm{C}_{2} \mathrm{D}_{2} \mathrm{Cl}_{4}, 100 \mathrm{MHz}\right): \delta=152.10,137.64$, 137.52 , 136.78, 136.68, 136.35, 135.55, 135.19, 134.60, 134.52, $134.01,133.23,132.42,131.80,130.94,130.66,130.20,128.77$, $128.30,127.92$, 127.90, 127.50, 127.41, 127.16, 127.13, 127.07, 127.02, 126.57, 126.36, 126.07, 126.04, 125.20, 124.84, 124.55; MALDI-TOF MS: $\mathrm{m} / z$ calcd for $\mathrm{C}_{78} \mathrm{H}_{40} \mathrm{~N}_{2} \mathrm{~S}_{19}$ (matrix: DCTB): 1611.8, found: 1612.1 ; HRMS: $m / z$ calcd for $\mathrm{C}_{78} \mathrm{H}_{40} \mathrm{~N}_{2} \mathrm{~S}_{19}$ : 1611.7885; found: 1611.7930 .

\subsection{Fabrication and characterization of the organic solar cells}

Photovoltaic devices were fabricated with the configuration of ITO/PEDOT:PSS/DOTs: $\mathrm{PC}_{61} \mathrm{BM}$ active layer/LiF/Al. The indium tin oxide (ITO) coated glass substrates were cleaned sequentially by ultrasonic in detergent, deionized water, acetone and isopropanol for $30 \mathrm{~min}$ each. After an additional treatment for 30 minutes in ultraviolet-ozone chamber, a thin layer (30-40 nm) of PEDOT:PSS (Clevios P VP AI 4083, filtered through $0.45 \mu \mathrm{m}$ ) was spin-coated onto each substrate at $3500 \mathrm{rpm}$ for $10 \mathrm{~min}$, the substrates were transferred into a nitrogen-filled glove box $\left(\mathrm{O}_{2}\right.$ and $\mathrm{H}_{2} \mathrm{O}<1 \mathrm{ppm}$ ). After annealing in a glove box at $124{ }^{\circ} \mathrm{C}$ for 1 min, the substrates were cooled to room temperature. Compound DOTs and $\mathrm{PC}_{60} \mathrm{BM}$ were dissolved in chloroform (CF), then stirred for $4 \mathrm{~h}$. The substrates were spin-coated with the solution of DOT-c-BT:PC ${ }_{61} \mathrm{BM}$ in chloroform to form the photoactive layer. The cathode made of $\operatorname{LiF}(1 \mathrm{~nm})$ and aluminum (100 $\mathrm{nm}$ ) was sequentially deposited by vacuum evaporation under high vacuum $\left(<10^{-4} \mathrm{~Pa}\right)$. The effective area of the devices was $0.16 \mathrm{~cm}^{2}$ and $0.09 \mathrm{~cm}^{2}$.

The current density-voltage $(J-V)$ characteristics was measured in a $\mathrm{N}_{2}$-filled glove box using a Keithley 2400 source meter under an AM 1.5G filter $\left(100 \mathrm{~mW} \mathrm{~cm}^{-2}\right)$ generated by white light from halogen tungsten lamp, filtered by a Schott GG385 UV filter and a Hoya LB120 daylight filter. External quantum efficiencies (EQE) were measured under simulated one sun operation condition using bias light from a $532 \mathrm{~nm}$ solid state laser (Changchun New Industries, MGL-III-532). Light from a $150 \mathrm{~W}$ tungsten halogen lamp (Osram 64610) was used as probe light and modulated with a mechanical chopper before passing the monochromator (Zolix, Omni- $\lambda 300$ ) to select the wavelength. The response was recorded as the 
voltage by an $I-V$ converter (DNR-IV Convertor, Suzhou D\&R Instruments), using a lock-in amplifier (Stanford Research Systems SR 830). A calibrated Si cell was used as reference. The device for EQE measurement was kept behind a quartz window in a nitrogen filled container.

\section{Results and discussion}

\subsection{Synthesis and structure characterization}

Synthesis. Scheme 1 displays the synthetic sequence for the target compounds. In this synthesis approach, 4,7-dibromo2,1,3-benzothiadiazole (BT-Br $\mathbf{~}_{2}$ ) was used as the core building unit. Trimethylsilyl (TMS) group were chosen as the terminal protecting group, owing to its high tolerance of basic reaction conditions and ease of further deprotection to give nonfunctionalized oligothiophenes. ${ }^{21,34}$ The dendritic oligothiophene precursors B-3T-Si and B-9T-Si were synthesized according to procedures reported previously. ${ }^{21,34}$ Finally, novel corefunctionalized three-dimensional (3D) $\pi$-conjugated dendritic oligothiophenes bearing benzothiadiazole group have been successfully synthesized by a convergent approach.

In detail, the TMS-protected first generation (G1) benzothiadiazole core-functionalized dendrimer 6T-c-BT-Si was obtained by Suzuki cross-coupling of the core building block BT$\mathbf{B r}_{2}$ and the first-generation (G1) dendritic boronic ester B-3T-Si at room temperature using $\left[\mathrm{Pd}_{2}(\mathrm{dba})_{3}\right] \cdot \mathrm{CHCl}_{3} / \mathrm{HP}(t-\mathrm{Bu})_{3} \mathrm{BF}_{4}$ as catalyst in $87 \%$ yield (Scheme 1, reaction (i)). The TMSprotecting groups of 6T-c-BT-Si were successfully removed by tetrabutylammonium fluoride hydrate (TBAF) in THF, thus yielding non-protected G1 dendrimer 6T-c-BT-H in 90\% yield (Scheme 1, reaction (ii)). The G1 dendrimers 6T-c-BT-Si and 6T-c-BT-H were efficiently purified by chromatography on silica gel.

The TMS-protected second-generation (G2) dendrimer 18T-cBT-Si was synthesized by Suzuki cross-coupling reaction of $\mathbf{B T}-\mathbf{B r}_{2}$ with two equivalents of the G2 boronic ester B-9T-Si in $80 \%$ yield. Similar to 6T-c-BT-H, the deprotected G2 dendrimer 18T-c-BT-H was synthesized by removing the TMS groups of 18T-c-BT-Si with TBAF in $85 \%$ yield. The purification of G2 dendrimers 18T-c-BT-Si and 18T-c-BT-H were performed by sizeexclusion chromatography (SEC, Bio-Rad Beads SX-1) eluting with THF.

Structural characterization. The chemical structures of the synthesized compounds were fully characterized by ${ }^{1} \mathrm{H}$ NMR, ${ }^{13} \mathrm{C}$ NMR, MALDI-TOF-MS and high resolution MS. Owing to the unsymmetrical and highly branched molecular structure of these dendrimers, ${ }^{1} \mathrm{H}$ NMR spectra of these compounds are rather complicated, especially for the higher-generation dendrimers. ${ }^{34}$ However, characteristic ${ }^{1} \mathrm{H}$ resonance peaks can be clearly identified for the low generation dendritic molecules. Fig. 1a shows the ${ }^{1} \mathrm{H}$ NMR spectra of these dendrimers in aromatic region. As can be seen from this figure, all these DOT-
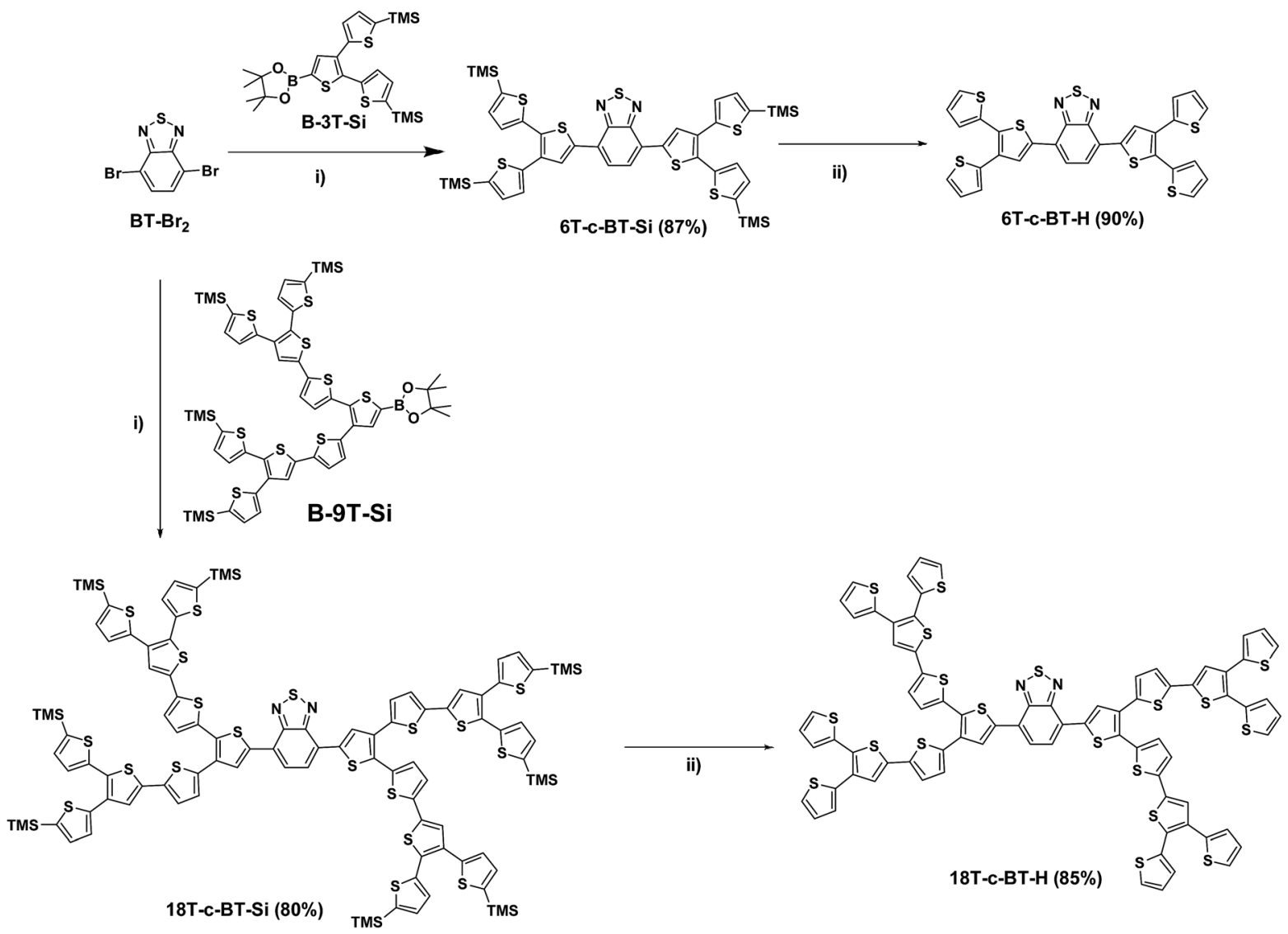

Scheme 1 (i), $\left[\mathrm{Pd}_{2}(\mathrm{dba})_{3}\right] \cdot \mathrm{CHCl}_{3}, \mathrm{HP}(t \mathrm{Bu})_{3} \mathrm{BF}_{4}, \mathrm{~K}_{2} \mathrm{CO}_{3}, \mathrm{THF}$; (ii), $\mathrm{Bu}_{4} \mathrm{NF} \cdot 3 \mathrm{H}_{2} \mathrm{O}, \mathrm{THF}$. 


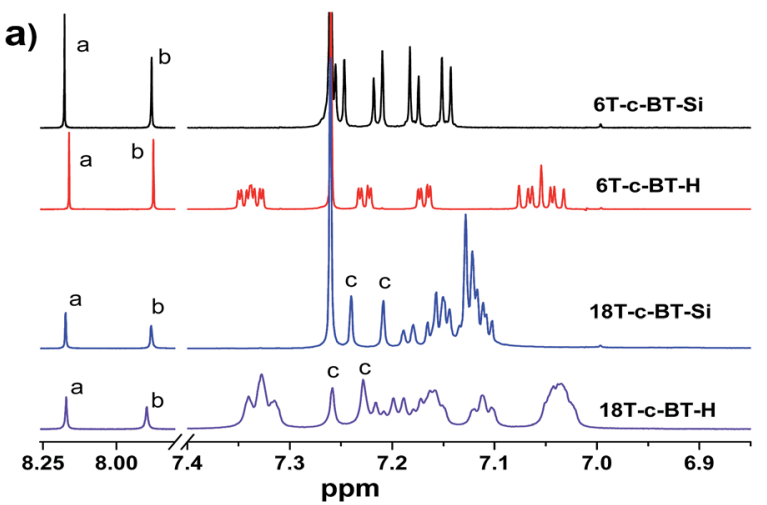

b)

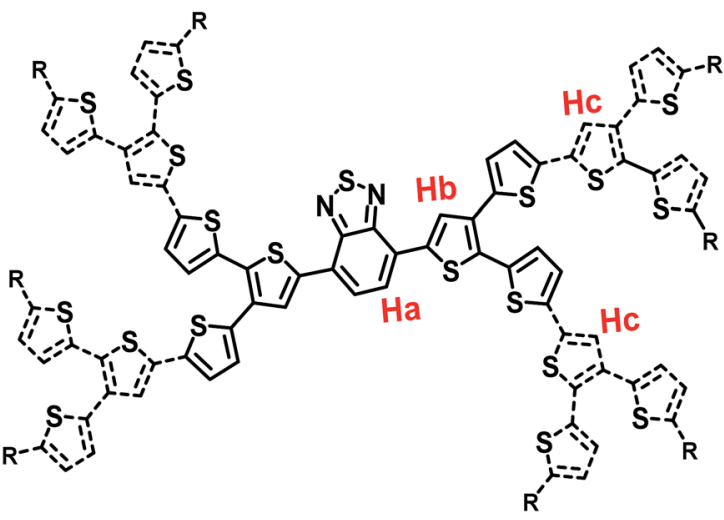

Fig. 1 (a) ${ }^{1} \mathrm{H}$ NMR spectra of $6 \mathrm{~T}-\mathrm{c}-\mathrm{BT}-\mathrm{Si}, 6 \mathrm{~T}-\mathrm{c}-\mathrm{BT}-\mathrm{H}, 18 \mathrm{~T}-\mathrm{c}-\mathrm{BT}-\mathrm{Si}$ (measured at room temperature in $\mathrm{CDCl}_{3}$ ) and $18 \mathrm{~T}-\mathrm{C}-\mathrm{BT}-\mathrm{Si}$ (measured at room temperature in $\mathrm{C}_{2} \mathrm{D}_{2} \mathrm{Cl}_{4}$ ) in the aromatic range; (b) chemical structure representation of DOT-c-BTs.

c-BTs showed characteristic ${ }^{1} \mathrm{H}$ resonance peak at $8.2 \mathrm{ppm}\left(\mathrm{H}_{\mathrm{a}}\right)$ and $7.9 \mathrm{ppm}\left(\mathrm{H}_{\mathrm{b}}\right)$, which are corresponding to the protons on the BT unit and the $\beta$-protons of thiophene ring next to the BT unit, respectively (see Fig. 1b). Two sets of singlet peaks of $\delta=$ $7.24,7.21 \mathrm{ppm}$ and $\delta=7.25,7.23 \mathrm{ppm}\left(\mathrm{H}_{\mathrm{c}}\right)$ were found for $18 \mathrm{~T}$ c-BT-Si and 18T-c-BT-H, respectively, which are assigned to the $\beta$-protons of the branching thiophene ring of the second generation (see also Fig. 1b). The integration ratio of the characteristic ${ }^{1} \mathrm{H}$ resonance peaks of $\mathrm{H}_{\mathrm{a}}: \mathrm{H}_{\mathrm{b}}: \mathrm{H}_{\mathrm{c}}$ is $1: 1: 2$, matching well the molecular structure. The ${ }^{1} \mathrm{H}$ resonance peaks become broader and featureless with the increase of molecular size, which was ascribed to more complicated molecular structure and stronger intermolecular interactions.

To further confirm the chemical structure of these compounds, the molecular weight of these BT corefunctionalized dendrimers were checked by GPC, MALDI-TOFMS and high-resolution mass-spectrometry analysis (HR MS, see ESI $\dagger$ for details). Fig. 2a shows the GPC traces for 18T-c-BT-H and 18T-c-BT-Si. The polydispersity indices (PDI) of these two dendritic molecules were a constant of 1.01, thus indicating a high degree of monodispersity of these two compounds. Fig. $2 \mathrm{~b}$ shows the MALDI-TOF mass spectrum of DOT-c-BTs. As can be seen here, all these compounds show one sharp molecular-ion peak, which indicated well-defined and monodisperse structures of these dendrimers. In addition, the HR MS patterns of the $2^{\text {nd }}$ generation derivatives (18T-c-BT-Si, and 18T-c-BT-H) fits very well the corresponding simulated one
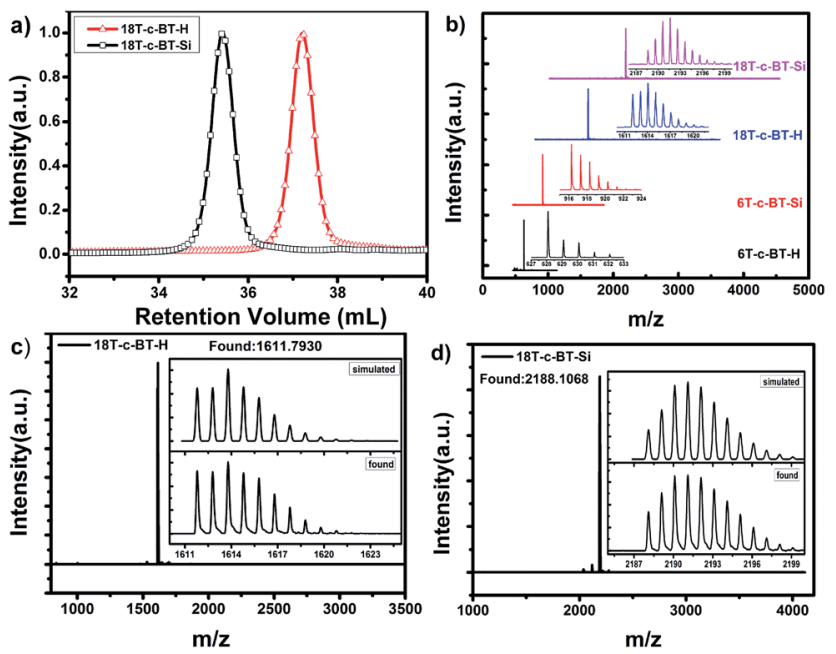

Fig. 2 (a) GPC traces of 18T-C-BT-Si and 18T-C-BT-H eluting with THF as the solvent; (b) MALDI-TOF mass spectra (matrix: DCTB) of DOT-c-BTs; (c, d) high-resolution mass-spectrometric characterization of derivatives $18 \mathrm{~T}-\mathrm{c}-\mathrm{BT}-\mathrm{H}$ and $18 \mathrm{~T}-\mathrm{C}-\mathrm{BT}-\mathrm{Si}$. The inset spectra show the isotopic patterns for each compound.

(Fig. 2c and d), unambiguously confirmed the chemical structure of these big molecules.

To investigate the effects of BT functional group on molecular geometries and electronic structures of these functionalized thiophene dendrimers, density functional theory (DFT) calculations were carried out by using the Gaussian 09 program with B3LYP/6-31G approach. Calculated optimal molecular conformations and the frontier molecular orbitals (FMOs) including highest occupied molecular orbital (HOMO) and the lowest unoccupied molecular orbital (LUMO) are shown in Fig. 3, and the related data are listed in Table 2. As shown in Fig. 3, the result obtained from optimized conformations suggests that the electron density distributions of the HOMO levels of all molecules are located in the longest $\alpha$-conjugated chain included in the corresponding dendrimers, indicating a strong and efficient intra-molecular charge transfer (ICT) interaction in the molecular backbones. At the same time, the electron density distributions of LUMO for BT corefunctionalized dendrimers is mainly localized on the electrondeficient BT units, while that of all-thiophene dendrimer (6T and $\mathbf{1 8 T}$ ) is located in the longest $\alpha$-conjugated chain (see details in ESI $\dagger$ ). Accordingly, the HOMO levels of BT corefunctionalized dendrimers vary only marginally with introducing of BT group compared with all-thiophene dendrimer. On the other hand, in comparison with corresponding allthiophene dendrimer, the LUMO levels of BT corefunctionalized dendrimers (6T-c-BT-H and 18T-c-BT-H) have a large decrease, which leads to a smaller band gap. Such a molecular orbital difference can be also seen from the UV-vis absorption spectra and cyclic voltammetry curves (vide infra).

\subsection{UV-vis absorption and fluorescence spectroscopy}

UV-vis and fluorescence spectroscopy of the BT corefunctionalized dendrimers were measured in chloroform. 

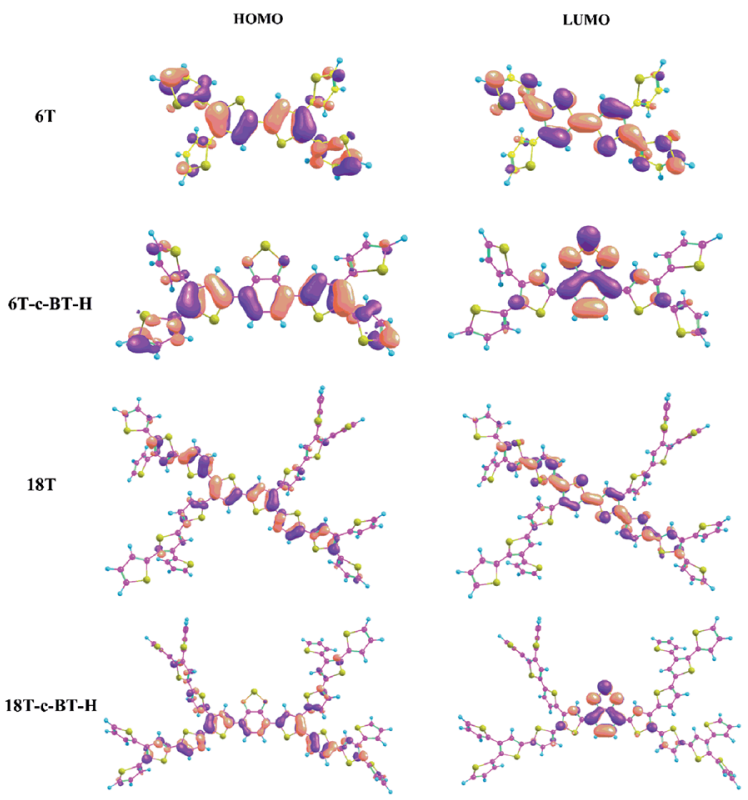

Fig. 3 DFT calculated optimal molecular conformations and molecular orbital surfaces of the HOMO and LUMO levels of conjugated dendrimers.
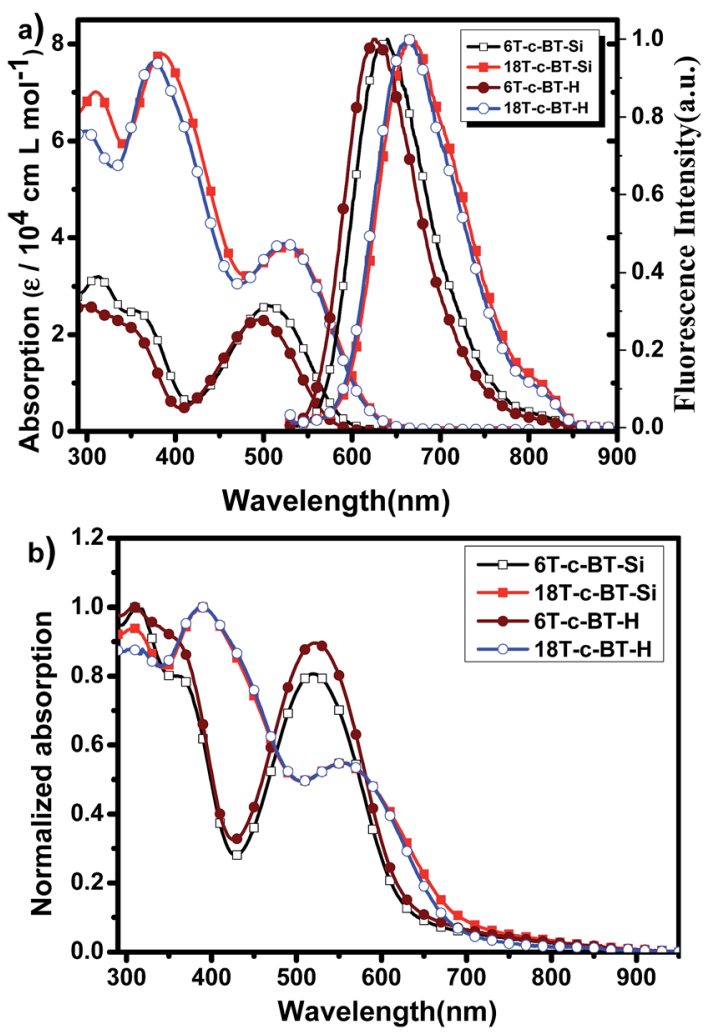

Fig. 4 (a) UV-vis absorption and normalized fluorescence spectra of DOT-c-BTs in chloroform solution $\left(1 \times 10^{-6} \mathrm{~mol} \mathrm{~L}^{-1}\right)$; (b) normalized UV-vis absorption spectra of DOT-c-BTs thin films.

Fig. 4a depicts the UV-vis absorption and fluorescence spectra of the synthesized DOT-c-BTs in chloroform solution, and the optical data are listed in Table 1. For comparison, the optical data of the reference compounds $\mathbf{6 T}$ and $\mathbf{1 8 T}$ are also listed in Table $1 .^{34}$ In comparison with all-thiophene dendrimers with the same number of thiophene units, the absorption onset of BT core-functionalized dendrimer show a significant redshift, which suggests the formation of intramolecular charge transfer state of the compounds owing to the introduction of BT units.

Similar to the all-thiophene dendrimers, ${ }^{21}$ these BTfunctionalized compounds displayed broad and structureless absorption bands (Fig. 4a). As can be seen from this figure, BT core-functionalized dendrimer showed two absorption bands. One high energy band is ranging from 300 to $450 \mathrm{~nm}$, which can be assigned to absorption of dendritic oligothiophenes. ${ }^{34}$ The other band located in the low energy band ranging of 450 to $650 \mathrm{~nm}$ can be assigned to an intramolecular charge transfer state between dendritic oligothiophenes and benzothiadiazole unit. Interestingly, the molar absorption coefficients of these BT cored dendrimers in both absorption bands increased with the increase of molecular generation. The increase of high energy bands was ascribed to the superimposition of the absorption of the conjugated oligothiophene unit, similar to that of the allthiophene dendrons and dendrimers,$^{34}$ whereas the increase of the low energy band indicates an more efficient intramolecular interaction between dendritic oligothiophenes and benzothiadiazole unit for the bigger molecules. As a general trend, bathochromic shifts of the absorption onset were observed clearly with increasing the generation of dendrimers. Optical band gap $\left(E_{\mathrm{g}}\right)$ of these compounds determined from the absorption onset $\lambda_{\mathrm{abs}}^{\text {onset }}$ decreases also with the increase of molecular size, which was ascribed to the larger $\pi$-conjugated oligothiophene building blocks. In addition, a sight redshift of absorption profile was observed for TMS-protecting dendrimers relative to their desilylated counterpart, which is similar to that in all-thiophene dendrons and dendrimers ${ }^{34}$ and was ascribed to the electron donating ability of the TMS groups. Fig. $4 \mathrm{~b}$ shows the absorption spectra of the DOT-c-BTs in thin solid film, compared with in chloroform solution, bathochromic shifts and broader absorption spectrum were observed obviously for BT core-functionalized dendrimers in thin solid films, which was ascribed to the intensive intermolecular interaction in solid state.

The fluorescence spectra of the BT core-functionalized dendrimers in chloroform are also shown in Fig. 4a. The fluorescence emission spectra can be considered as the result of the electronic transition of the longest-conjugated chromophore included in the corresponding dendrimers. ${ }^{34}$ The maximum emission wavelengths $\left(\lambda_{\mathrm{fl}}^{\max }\right)$ of the DOT-c-BTs are obviously redshifted with the increase of molecular size from $1^{\text {st }}$ generation to $2^{\text {nd }}$ generation, indicating a more expanded $\pi$-conjugated system for the larger dendrimers, which is in accordance with the trend of the UV-vis absorption onset wavelength. In addition, similarly to their all-thiophene dendrimers, ${ }^{34}$ the fluorescence profile typically is independent of the excitation wavelength (see ESI Fig. S1† for more details), which indicates an efficient intramolecular energy transfer. Compared to allthiophene dendrimers, $\lambda_{\mathrm{fl}}^{\max }$ of the BT core-functionalized dendrimers shows an obvious redshift, which confirms that 
Table 1 Absorption and fluorescence data of dendrimers

\begin{tabular}{|c|c|c|c|c|c|c|c|c|}
\hline Compound & $\lambda_{\max }^{\mathrm{sol} a}(\mathrm{~nm})$ & $\varepsilon^{\mathrm{sol} a, b}\left[\mathrm{~cm}^{-1} \mathrm{~L} \mathrm{~mol}^{-1}\right]$ & $\lambda_{\text {onset }}^{\text {sol } a}(\mathrm{~nm})$ & $\lambda_{\max }^{\mathrm{em} c}(\mathrm{~nm})$ & $E_{\mathrm{g}}^{\mathrm{opt}(\mathrm{sol}) a, d}(\mathrm{eV})$ & $\lambda_{\max }^{\text {filme }}(\mathrm{nm})$ & $\lambda_{\text {onset }}^{\text {film }} e(\mathrm{~nm})$ & $E_{\mathrm{g}}^{\mathrm{opt}(\mathrm{film}) e_{2} f}(\mathrm{eV})$ \\
\hline 6T-c-BT-Si & 506 & 26230 & 588 & 640 & 2.10 & 520 & 629 & 1.97 \\
\hline 6T-c-BT-H & 495 & 23060 & 576 & 626 & 2.15 & 522 & 632 & 1.96 \\
\hline & 384 & 21600 & & & & & & \\
\hline \multirow[t]{2}{*}{ 18T-c-BT-Si } & 384 & 77900 & 623 & 667 & 1.99 & 556 & 694 & 1.79 \\
\hline & 524 & 37650 & & & & & & \\
\hline $18 \mathrm{~T}^{g}$ & 392 & 78000 & 528 & 554 & 2.35 & - & - & - \\
\hline
\end{tabular}

${ }^{a}$ In $\mathrm{CHCl}_{3}$ solution $\left(10^{-6} \mathrm{~mol} \mathrm{~L}^{-1}\right) \cdot{ }^{b}$ Extinction coefficient in solution was obtained by linear fitting absorbance $v s$. concentration. ${ }^{c}$ The maxima emission peak with the excitation wavelength. ${ }^{d}$ Optical band gap estimated from the absorption edge in solution, $E_{\mathrm{g}}^{\text {opt(sol) }}(\mathrm{eV})=1240 / \lambda_{\mathrm{onset}}^{\text {sol }}(\mathrm{nm})$. ${ }^{e}$ Spin-coated from $\mathrm{CHCl}_{3}$ solution onto the quartz. ${ }^{f}$ Optical band gap in solid film, $E_{\mathrm{g}}^{\text {opt(film) }}(\mathrm{eV})=1240 / \lambda_{\text {onset }}^{\text {film }}(\mathrm{nm}) .{ }^{g}$ From ref. 34 .

the attachment of BT unit efficiently expands the conjugated length of dendrimers.

\subsection{Redox properties and molecular energy levels}

The electrochemical properties of the BT core-functionalized dendrimers were investigated by cyclic voltammetry (CV) and differential pulse voltammetry (DPV) in dichloromethane (for 18T-c-BT-H, it was measured in $o$-dichlorobenzene due to the low solubility) with $\mathrm{Bu}_{4} \mathrm{NPF}_{6}$ as supporting electrolyte. Fig. 5a shows cyclic voltammograms of DOT-c-BTs, and the DPV curves of these compounds are shown in Fig. S2 in ESI. $\dagger$ Interestingly, all these compounds showed one reversible reduction process over the negative potential range $(0$ to $-2.0 \mathrm{~V})$, the reversible reduction process was ascribed to the reduction of the BT core unit. The standard reduction potentials were determined to be around $-1.6 \mathrm{~V}$ vs. $\mathrm{Fc}^{+} / \mathrm{Fc}$ and vary only marginally with increasing molecular size, suggesting that the peripheral DOT units do not influence the redox behavior of the BT core.

In the positive potential regime, the oxidation potentials of these compounds depend on the molecular structure. For example, the $1^{\text {st }}$ generation TMS-protected dendrimer 6T-c-BTSi displays two reversible oxidation processes $\left(E_{\mathrm{ox}}^{0}=0.53\right.$, and $0.67 \mathrm{~V}$, respectively) during the positive potential sweeping. For 18T-c-BT-Si, two reversible oxidation processes were measured with $E_{\mathrm{Ox}}^{0}=0.31,0.47 \mathrm{~V}$, respectively. Reversible oxidation processes confirm that the oxidized species of the DOT-c-BTs molecules are stable in solution during the potential sweeping. ${ }^{34}$ First oxidative potential for higher generational dendrimers was estimated from DPV measurements. It worth also to note that, the onset oxidation potential is negatively shifted with increasing molecular size due to extended $\pi$ conjugation, which is in accordance with the UV/vis spectroscopic results. Similar to non-protected all-thiophene dendrons and dendrimers, ${ }^{34}$ the TMS-free DOT-c-BTs undergo electropolymerization during potential sweeping, yielding corresponding hyperbranched polymers (Fig. $5 \mathrm{c}$ and d).

HOMO/LUMO energy levels as well as the band gaps $\left(E_{\mathrm{g}}^{\mathrm{CV}}\right)$ of these compounds were determined from the onset oxidation ( $\left.E_{\mathrm{ox}}^{\text {onset }}\right)$ and the onset reduction potentials ( $\left.E_{\text {red }}^{\text {onset }}\right)$ according to eqn (1) and (2),

$$
\begin{gathered}
E_{\mathrm{HOMO}}=-\left(E_{\mathrm{ox}}^{\mathrm{onset}}+5.10\right)(\mathrm{eV}) \\
E_{\mathrm{LUMO}}=-\left(E_{\mathrm{red}}^{\mathrm{onset}}+5.10\right)(\mathrm{eV}) \\
E_{\mathrm{g}}^{\mathrm{CV}}=E_{\mathrm{ox}}^{\mathrm{onset}}-E_{\mathrm{red}}^{\mathrm{onset}}(\mathrm{eV})
\end{gathered}
$$

whereby $E_{\mathrm{ox}}^{\text {onset }}$ and $E_{\mathrm{red}}^{\text {onset }}$ represent the onset oxidation and the onset reduction potential value relative to the ferrocene/ ferrocenium couple, respectively, for which an energy level of $-5.10 \mathrm{eV}$ versus vacuum was taken. ${ }^{35}$ HOMO-LUMO energy levels of DOT-c-BTs derived from electrochemical data are listed
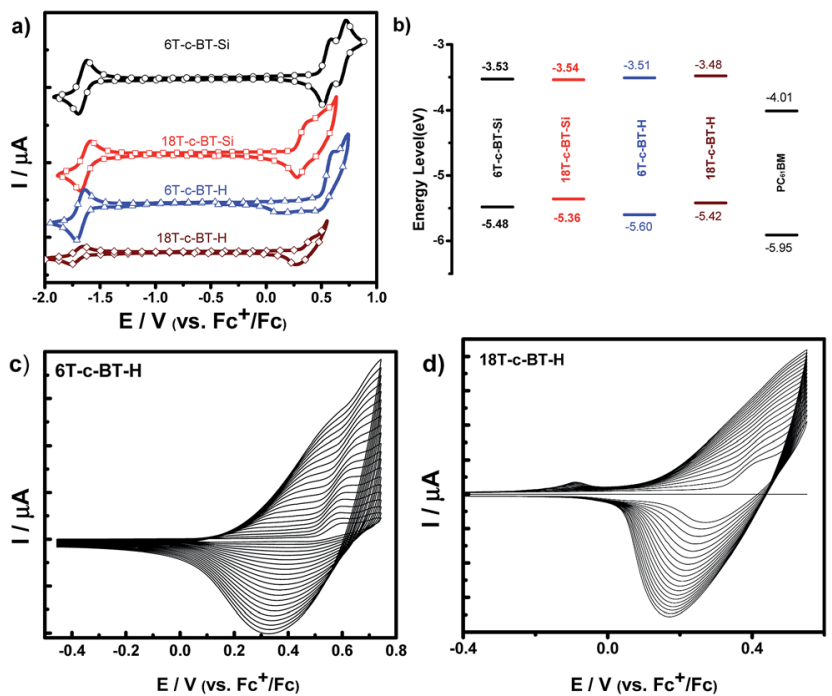

Fig. 5 (a) Cyclic voltammograms of $6 \mathrm{~T}-\mathrm{c}-\mathrm{BT}-\mathrm{Si}, 18 \mathrm{~T}-\mathrm{c}-\mathrm{BT}-\mathrm{Si}, 6 \mathrm{~T}-\mathrm{c}-$ BT-H $\left(1 \times 10^{-3} \mathrm{~mol} \mathrm{~L}^{-1}\right.$ in $\left.\mathrm{CH}_{2} \mathrm{Cl}_{2}\right), 18 \mathrm{~T}-\mathrm{c}-\mathrm{BT}-\mathrm{H}\left(1 \times 10^{-3} \mathrm{~mol} \mathrm{~L}^{-1}\right.$ in odichlorobenzene) tetrabutylammonium hexafluorophosphate $\left(\right.$ TBAPF $_{6}, 0.1 \mathrm{M}$ ), scan rate $=100 \mathrm{mV} \mathrm{s}^{-1}$ versus ferrocene/ferrocenium $\left(\mathrm{Fc}^{+} / \mathrm{Fc}\right)$; (b) representation of HOMO-LUMO energy levels of selected dendritic compounds obtained by electrochemical data. The values for $\mathrm{PC}_{61} \mathrm{BM}$ are also given for comparison and were taken from reference, $^{36}$ (c) multiple scans cyclic voltammogram of $6 \mathrm{~T}-\mathrm{c}-\mathrm{BT}-\mathrm{H}$ at $1 \times$ $10^{-3} \mathrm{~mol} \mathrm{~L}^{-1}$ in $\mathrm{CH}_{2} \mathrm{Cl}_{2}$ (TBAPF 6 (0.1 M), room temperature, $V=$ $100 \mathrm{mV} \mathrm{s}^{-1}$ ); (d) multiple scans cyclic voltammogram of $18 \mathrm{~T}-\mathrm{c}-\mathrm{BT}-\mathrm{H}$ at $1 \times 10^{-3} \mathrm{~mol} \mathrm{~L}{ }^{-1}$ in o-dichlorobenzene (TBAPF 6 (0.1 M), room temperature, $V=100 \mathrm{mV} \mathrm{s}^{-1}$ ). 
Table 2 Electrochemical characterization of DOT-c-BTs ${ }^{a}$

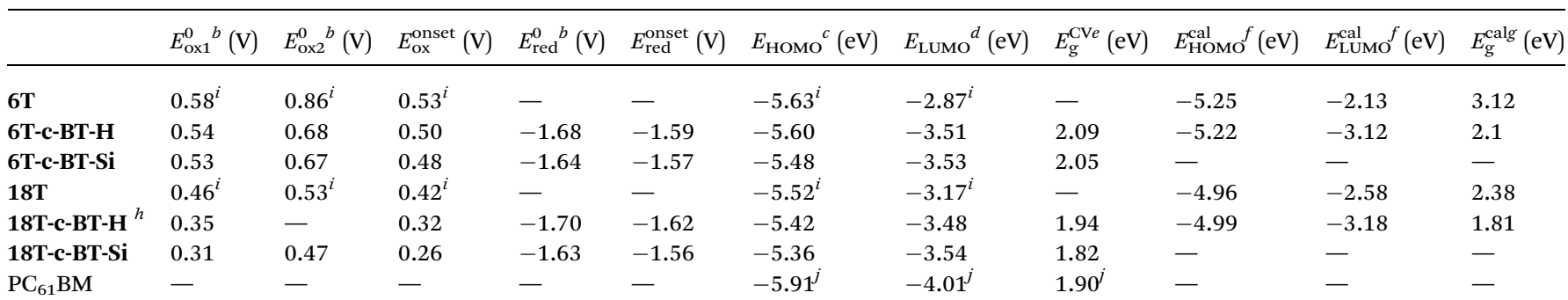

${ }^{a}[\mathrm{M}]=1 \times 10^{-3} \mathrm{~mol} \mathrm{~L}^{-1}$ in $\mathrm{CH}_{2} \mathrm{Cl}_{2}, \mathrm{TBAPF}_{6}(0.1 \mathrm{M}), 295 \mathrm{~K}, V=100 \mathrm{mV} \mathrm{s}^{-1}$, versus $\left(\mathrm{Fc}^{+} / \mathrm{Fc}\right) .{ }^{b}$ Determined by DPV measurements. ${ }^{c}$ Calculated from the cyclic voltammograms, $E_{\mathrm{HOMO}}=-\left[E_{\mathrm{Ox}}^{\mathrm{onset}}+5.10\right](\mathrm{eV})$, where the vacuum energy level of $\mathrm{Fc}^{+} / \mathrm{Fc}$ was set as $-5.10 \mathrm{eV}$. ${ }^{d} \mathrm{Calculated}$ from the cyclic

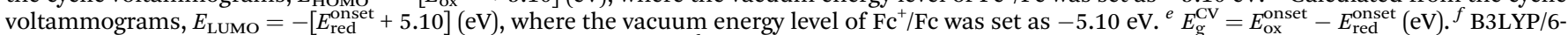
$31 \mathrm{G}$ energies by DFT. ${ }^{g}$ B3LYP/6-31G HOMO-LUMO energy gaps. ${ }^{h}[\mathrm{M}]=1 \times 10^{-3} \mathrm{~mol} \mathrm{~L}^{-1}$ in $o$-dichlorobenzene, TBAPF $6(0.1 \mathrm{M}), 295 \mathrm{~K}, V=100 \mathrm{mV}$ $\mathrm{s}^{-1}$, versus $\left(\mathrm{Fc}^{+} / \mathrm{Fc}\right) .{ }^{i}$ From ref. $34 .^{j}$ From ref. 36.

in Table 2, and the energy level alignment of the DOT-c-BTs is depicted in Fig. $5 \mathrm{~b}$ and compared to that of $\mathrm{PC}_{61} \mathrm{BM}^{36} \mathrm{As}$ can be seen from Table 2, the HOMO energy levels of the BT-cored dendrimer 6T-c-BT-H and 18T-c-BT-H are similar to that of the corresponding all-thiophene dendrimer $\mathbf{6 T}$ and $18 \mathrm{~T}$, suggesting that the core BT unit have marginal influence on the HOMO energy levels of the dendrimers, which is also supported by the theoretical calculation results (vide supra). Whereas the LUMO energy levels of the dendrimers decreased dramatically to $\sim-3.5 \mathrm{eV}$ when BT was introduced as the core-unit, leading to a much smaller optical band gap. The LUMO energy level differences between the DOT-c-BT and $\mathrm{PC}_{61} \mathrm{BM}$ are more than $0.5 \mathrm{eV}$, which provides sufficient driving force for the intermolecular charge transfer between these two materials, suggesting that DOT-c-BTs could be used as electron donor in organic solar cells by blending with $\mathrm{PC}_{61} \mathrm{BM}$. The similar HOMO energy levels of BT-cored dendrimers as the all-thiophene dendrimers, on the other hand, will keep high $V_{\mathrm{OC}}$ for the BT-cored dendrimers based solar cells as that of all-thiophene dendrimer based cells. ${ }^{14 a}$

\subsection{Application of these compounds as electron donor in organic solar cells}

To evaluate the photovoltaic performances of the novel synthesized BT core-functionalized DOTs molecules, solution processed photovoltaic devices were fabricated with the structure: ITO/PEDOT:PSS/DOT-c-BT:PC ${ }_{61} \mathrm{BM} / \mathrm{LiF} / \mathrm{Al}$, where DOT-c$\mathrm{BT}$ molecules were used as the electron donor and $\mathrm{PC}_{61} \mathrm{BM}$ as the electron acceptor components. The thickness of the photoactive layers optimized for each DOT-c-BT: $\mathrm{PC}_{61} \mathrm{BM}$ by varying the spin speed during spin-coating and the concentration of solution was found to be around $60-80 \mathrm{~nm}$. The current-voltage $(J-V)$ curves under simulated AM1.5G illumination and EQE response spectra of the optimized devices are shown in Fig. 6a and $b$, respectively. The optimized photovoltaic performance of the DOT-c-BT devices was summarized in Table 3. As can be seen from the Table 3, the open circuit voltages $\left(V_{\mathrm{OC}}\right)$ for these DOT-c-BT based devices are in the range of 0.81-1.06 V. For first generation dendrimers 6T-c-BT-Si and 6T-c-BT-H, the $V_{\mathrm{OC}}$ values even up to $1.04 \mathrm{~V}$ and $1.06 \mathrm{~V}$, respectively, which are similar to that in all-thiophene dendrons and dendrimers. ${ }^{14 a}$
The first-generation TMS-free dendrimer, 6T-c-BT-H, when blended with $\mathrm{PC}_{61} \mathrm{BM}$, displayed a short-circuit current density $\left.U_{\mathrm{sC}}\right)$ of $2.42 \mathrm{~mA} \mathrm{~cm}{ }^{-2}$, an open-circuit voltage $\left(V_{\mathrm{OC}}\right)$ of $1.06 \mathrm{~V}$, and a fill factor (FF) of 0.35 , leading to an overall power conversion efficiency (PCE) of $1.04 \%$. The $V_{\mathrm{OC}}$ was found to be decreased with the increase of molecular size, which may be ascribed to the slightly higher HOMO energy level for the larger molecules (vide supra). However, all these BT based photovoltaic devices showed relative low power conversion efficiency owing to the low $J_{\mathrm{SC}}$ and low $\mathrm{FF}$ values. The low $J_{\mathrm{SC}}$ can be attributed to the poor EQE response of the devices. As can be seen from Fig. 6b, EQE spectra of these devices also showed low incident photon-to-current efficiency.
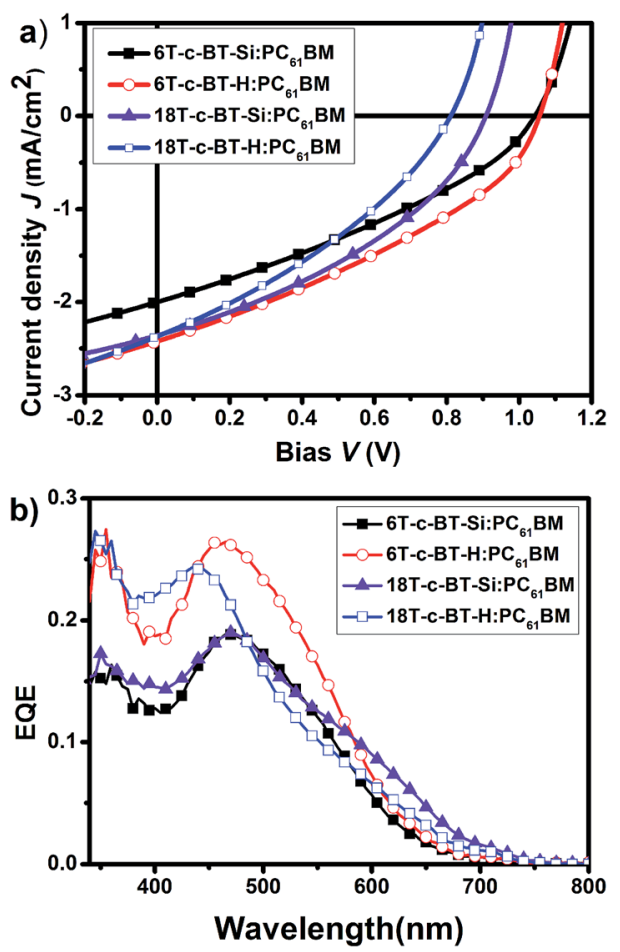

Fig. 6 (a) J-V curves of the optimized DOT-C-BT:PC ${ }_{61} B M$ based $B H J$ solar cells illuminated under standard AM1.5G conditions $(100 \mathrm{~mW}$ $\mathrm{cm}^{-2}$ ); (b) EQE spectra of the corresponding devices. 
Table 3 Characterization of bulk heterojunction solar cells containing BT-functionalized dendritic oligothiophenes as the donor material and $\mathrm{PC}_{61} \mathrm{BM}$ as the acceptor $^{a}$

\begin{tabular}{|c|c|c|c|c|c|c|c|}
\hline Donor & Acceptor & $\mathrm{EQE}_{\max }^{b}$ (wavelength [nm]) & $\mathrm{D}: \mathrm{A}$ & $J_{\mathrm{SC}}^{c}\left[\mathrm{~mA} \mathrm{~cm}{ }^{2}\right]$ & $V_{\mathrm{OC}}[\mathrm{V}]$ & $\mathrm{FF}$ & PCE [\%] \\
\hline 6T-c-BT-Si & $\mathrm{PC}_{61} \mathrm{BM}$ & $0.19(465)$ & $1: 2$ & 2.00 & 1.04 & 0.33 & 0.67 \\
\hline 6T-c-BT-H & & $0.26(465)$ & $1: 3$ & 2.42 & 1.06 & 0.35 & 1.04 \\
\hline 18T-c-BT-H & & $0.24(435)$ & $1: 3$ & 2.37 & 0.81 & 0.34 & 0.65 \\
\hline 6T-c-BT-Si & $\mathrm{PC}_{71} \mathrm{BM}$ & $0.18(500)$ & $1: 2$ & 2.32 & 0.92 & 0.27 & 0.58 \\
\hline 6T-c-BT-H & & $0.28(505)$ & $1: 2$ & 3.70 & 1.04 & 0.32 & 1.23 \\
\hline 18T-Si ${ }^{d}$ & $\mathrm{PC}_{61} \mathrm{BM}$ & $0.28(435)$ & $1: 4$ & 2.39 & 0.94 & 0.35 & 0.79 \\
\hline
\end{tabular}

${ }^{a}$ With a standard device structure of ITO/PEDOT:PSS/DOT-c-BT:PC ${ }_{61} \mathrm{BM}$ or $\mathrm{PC}_{71} \mathrm{BM} / \mathrm{LiF} / \mathrm{Al} .{ }^{b}$ External quantum efficiencies (EQE) were measured under simulated one sun operation condition using bias light from a $532 \mathrm{~nm}$ solid state laser. ${ }^{c} J_{\mathrm{SC}}$ determined by integrating the EQE spectrum with the AM1.5 G spectrum. ${ }^{d}$ From ref. $14 a$.

To further understand the photovoltaic performance of these DOT-c-BT, bulk heterojunction solar cells based on $\mathrm{IC}_{61} \mathrm{BA}$ and $\mathrm{PC}_{71} \mathrm{BM}$ were fabricated and tested. The $\mathrm{IC}_{61} \mathrm{BA}$ based cells showed very poor device performance, which was mainly due to the low $J_{\mathrm{SC}}$ of these devices (ESI Fig. $\mathrm{S} 3 \dagger$ ). The $\mathrm{PC}_{71} \mathrm{BM}$ based cells, on the other hand, showed improved $J_{\mathrm{SC}}$ than that of the $\mathrm{PC}_{61} \mathrm{BM}$ based cells, mainly due to the improved $J_{\mathrm{SC}}$ as can be seen from the $J-V$ and EQE spectra (Fig. 7 and Table 3), and higher PCE were achieved for the DOT-c-BT based cells, except for the 6T-c-BT-Si cell.

To understand the intermolecular interactions between these DOT-c-BT and $\mathrm{PC}_{61} \mathrm{BM}$, fluorescence quenching of the $6 \mathrm{~T}$ -
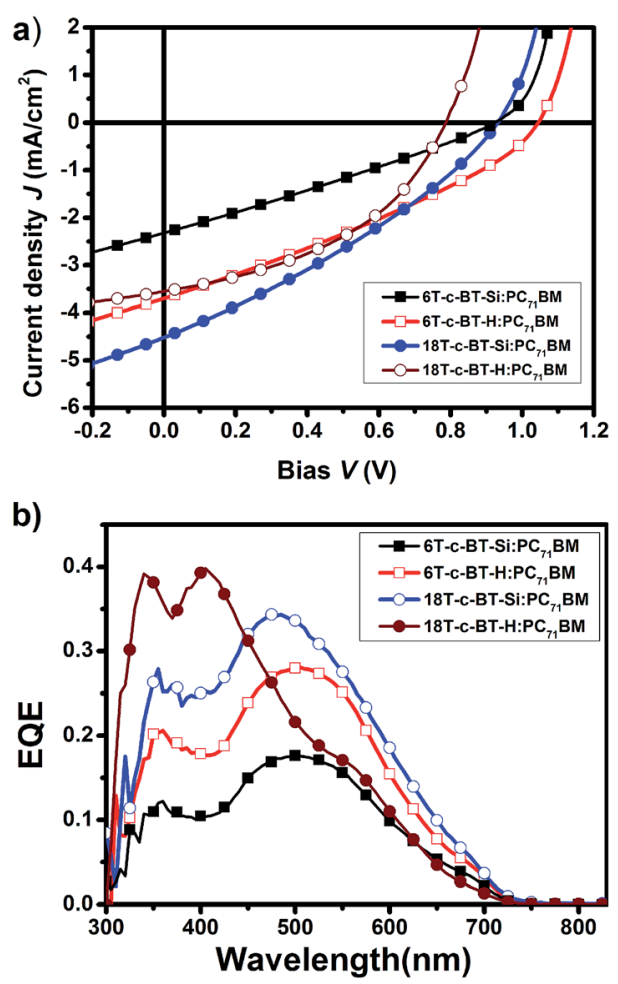

Fig. 7 (a) J-V curves of the optimized DOT-C-BT:PC ${ }_{71} B M$ based $B H J$ solar cells illuminated under standard AM1.5G conditions $(100 \mathrm{~mW}$ $\mathrm{cm}^{-2}$ ); (b) EQE spectra of the corresponding devices.
c-BT-H and 18T-c-BT-Si with $\mathrm{PC}_{61} \mathrm{BM}$ were carried out. Fig. S4† depicts the fluorescence quenching results. For comparison, the fluorescence quenching of P3HT film was also measured, and the results are showed in Fig. S4c. $\dagger$ As can be seen here, the fluorescence of 6T-c-BT and 18T-c-BT-Si was fully quenched by mixing with $\mathrm{PC}_{61} \mathrm{BM}$ with a blend ratio of $1: 1(\mathrm{w} / \mathrm{w})$. The fluorescence quenching efficiency was even higher for 6T-c-BT$\mathbf{H}$ and 18T-c-BT-Si than P3HT. These results demonstrate that intermolecular charge transfer between DOT-c-BT and fullerene is very efficient. On the other hand, these results indicate also that DOT-c-BT molecules are well intermixed with fullerene molecules, which might lead to less phase separation.

To better understand the reason for the low device performance, the photoactive layer morphology of DOT-c-BT:PC ${ }_{61} \mathrm{BM}$ blend film was measured by transmission electron microscope (TEM). Fig. 8 presents TEM images of the DOT-c-BT:PC ${ }_{61} \mathrm{BM}$

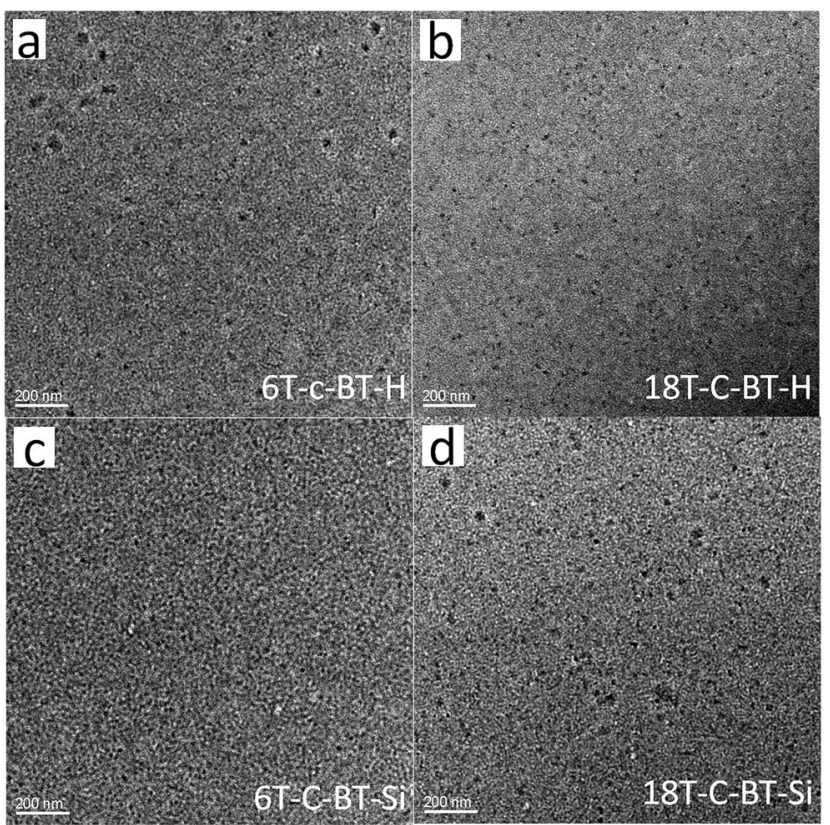

Fig. 8 Bright-field TEM images of DOT-c-BTs:PC ${ }_{61} B M$ blend films. (a) $6 \mathrm{~T}-\mathrm{c}-\mathrm{BT}-\mathrm{H}$; (b) 18T-c-BT-H; (c) 6T-c-BT-Si; (d) 18T-c-BT-Si. 
films fabricated under the optimal conditions. The images of DOT-c-BT:PC ${ }_{61} \mathrm{BM}$ show uniform and almost featureless contrast, indicating a low degree of phase separation. The unfavorable morphology would not facilitate efficient exciton dissociation. At the same time, the morphology also lacks bicontinuous interpenetrating network, which is essential to effective exciton dissociation and carrier transport. ${ }^{37}$ In the process of fabricating solar cells, the TMS-containing dendrimers displayed good solubility in common organic solvents. However, for G2 TMS-free dendrimers (18T-c-BT-H) had very low solubility, which may lead to poor film formation by spin coating process. Further optimization of nanomorphology by various approaches is still needed to achieve high device performance.

\section{Conclusions}

In summary, a novel series of three dimensional conjugated dendritic oligothiophenes with BT unit at the core were synthesized by a stepwise synthesis approach. The chemical structures of all these BT core-functionalized DOTs are fully characterized, including NMR, GPC, MALDI-TOF-MS and HRMS. Both MS and GPC analysis showed the monodisperse nature of these molecules. Characterization of the optical and electrochemical properties of the BT core-functionalized DOTs revealed that the BT groups linked to the dendritic oligothiophene yielded a bathochromic shift in the absorption spectra and a smaller optical band gaps compared with all-thiophene dendrimers. Preliminary applications in organic photovoltaic devices of these BT core-functionalized DOTs showed a moderate performance with efficiencies in the range from 0.58 to $1.35 \%$. Unfavorable nanophase separation in the blend films was the main reason for the low $J_{\mathrm{SC}}$ of these devices.

\section{Acknowledgements}

The authors greatly appreciate the financial supports from the National Natural Science Foundation of China (Grant No. 21274163, 21573020, 21303252) and Natural Science Foundation of Jiangsu Province (Grant No. BK20130352).

\section{Notes and references}

1 (a) M. E. Cinar and T. Ozturk, Chem. Rev., 2015, 115, 30363140; (b) D. Fichou, Handbook of Oligo- and Polythiophenes, Wiley-VCH, New York, 2007; (c) I. F. Perepichka and D. F. Perepichka, Handbook of Thiophene-based Materials: Applications in Organic Electronics and Photonics, John Wiley \& Sons, Ltd, 2009.

2 (a) A. Mishra, C.-Q. Ma and P. Bäuerle, Chem. Rev., 2009, 109, 1141-1276; (b) R. Fitzner, E. Reinold, A. Mishra, E. MenaOsteritz, H. Ziehlke, C. Körner, K. Leo, M. Riede, M. Weil, O. Tsaryova, A. Weiß, C. Uhrich, M. Pfeiffer and P. Bäuerle, Adv. Funct. Mater., 2011, 21, 897-910; (c) Y. Chen, X. Wan and G. Long, Acc. Chem. Res., 2013, 46, 2645-2655; (d) M. Zhang, X. Guo, W. Ma, H. Ade and J. Hou, Adv. Mater.,
2014, 26, 5880-5885; (e) V. Malytskyi, J.-J. Simon, L. Patrone and J.-M. Raimundo, RSC Adv., 2015, 5, 354-397. 3 (a) C. Wang, H. Dong, W. Hu, Y. Liu and D. Zhu, Chem. Rev., 2012, 112, 2208-2267; (b) X. Gao and Z. Zhao, Sci. China: Chem., 2015, 58, 947-968; (c) P. H. Chu, L. Zhang, N. S. Colella, B. Fu, J. O. Park, M. Srinivasarao, A. L. Briseno and E. Reichmanis, ACS Appl. Mater. Interfaces, 2015, 7, 6652-6660.

4 C. Zhang, P. Chen and W. Hu, Small, 2016, 12, 1252-1294.

5 F. Perepichka, D. F. Perepichka, H. Meng and F. Wudl, $A d v$. Mater., 2005, 17, 2281-2305.

6 (a) F. Zhang, G. Gotz, H. D. Winkler, C. A. Schalley and P. Bauerle, Angew. Chem., Int. Ed., 2009, 48, 6632-6635; (b) M. Iyoda and H. Shimizu, Chem. Soc. Rev., 2015, 44, 64116424.

7 (a) X. B. Sun, Y. Q. Liu, S. Y. Chen, W. F. Qiu, G. Yu, Y. Q. Ma, T. Qi, H. J. Zhang, X. J. Xu and D. B. Zhu, Adv. Funct. Mater., 2006, 16, 917-925; (b) X. B. Sun, Y. H. Zhou, W. C. Wu, Y. Q. Liu, W. J. Tian, G. Yu, W. F. Qiu, S. Y. Chen and D. B. Zhu, J. Phys. Chem. B, 2006, 110, 7702-7707; (c) H. Shang, H. Fan, Y. Liu, W. Hu, Y. Li and X. Zhan, J. Mater. Chem., 2011, 21, 9667-9673.

8 T. Jarosz, M. Lapkowski and P. Ledwon, Macromol. Rapid Commun., 2014, 35, 1006-1032.

9 (a) C.-Q. Ma, Frontiers of Optoelectronics in China, 2011, 4, 1223; (b) M. Scheuble, M. Goll and S. Ludwigs, Macromol. Rapid Commun., 2015, 36, 115-137.

10 H. John, R. Bauer, P. Espindola, P. Sonar, J. Heinze and K. Mullen, Angew. Chem., Int. Ed., 2005, 44, 2447-2451.

11 F. Zhang, D. Wu, Y. Xu and X. Feng, J. Mater. Chem., 2011, 21, 17590.

12 (a) D. Ni, B. Zhao, T. Shi, S. Ma, G. Tu and H. Wu, ACS Macro Lett., 2013, 2, 621-624; (b) Y. Lin and X. Zhan, Acc. Chem. Res., 2016, 49, 175-183.

13 M. E. Köse, W. J. Mitchell, N. Kopidakis, C. H. Chang, S. E. Shaheen, K. Kim and G. Rumbles, J. Am. Chem. Soc., 2007, 129, 14257-14270.

14 (a) C.-Q. Ma, M. Fonrodona, M. C. Schikora, M. M. Wienk, R. A. J. Janssen and P. Bäuerle, Adv. Funct. Mater., 2008, 18, 3323-3331; (b) A. Mishra, C.-Q. Ma, R. A. J. Janssen and P. Bäuerle, Chem.-Eur. J., 2009, 15, 13521-13534; (c) A. J. Mozer, C.-Q. Ma, W. W. H. Wong, D. J. Jones, P. Bäuerle and G. G. Wallace, Org. Electron., 2010, 11, 573582.

15 A. L. Kanibolotsky, I. F. Perepichka and P. J. Skabara, Chem. Soc. Rev., 2010, 39, 2695-2728.

16 (a) B. A. Hammer and K. Müllen, Chem. Rev., 2016, 116, 2103-2140; (b) B. A. Hammer, R. Moritz, R. Stangenberg, M. Baumgarten and K. Mullen, Chem. Soc. Rev., 2015, 44, 4072-4090; (c) A. J. Berresheim, M. Müller and K. Müllen, Chem. Rev., 1999, 99, 1747-1785.

17 J. S. Moore, Acc. Chem. Res., 1997, 30, 402-413.

18 K. Shi, J. Y. Wang and J. Pei, Chem. Rec., 2015, 15, 52-72.

19 (a) J. Ding, B. Zhang, J. Lu, Z. Xie, L. Wang, X. Jing and F. Wang, Adv. Mater., 2009, 21, 4983-4986; (b) J. Li, T. Zhang, Y. Liang and R. Yang, Adv. Funct. Mater., 2013, 23, 619-628; (c) P. Thongkasee, A. Thangthong, 
N. Janthasing, T. Sudyoadsuk, S. Namuangruk, T. Keawin, S. Jungsuttiwong and V. Promarak, ACS Appl. Mater. Interfaces, 2014, 6, 8212-8222.

20 (a) C. Xia, X. Fan, J. Locklin and R. C. Advincula, Org. Lett., 2002, 4, 2067-2070; (b) C. Xia, X. Fan, J. Locklin, R. C. Advincula, A. Gies and W. Nonidez, J. Am. Chem. Soc., 2004, 126, 8735-8743.

21 C.-Q. Ma, E. Mena-Osteritz, T. Debaerdemaeker, M. M. Wienk, R. A. J. Janssen and P. Bäuerle, Angew. Chem., Int. Ed., 2007, 46, 1679-1683.

22 (a) W. J. Mitchell, N. Kopidakis, G. Rumbles, D. S. Ginley and S. E. Shaheen, J. Mater. Chem., 2005, 15, 4518-4528; (b) M. Mastalerz, V. Fischer, C.-Q. Ma, R. A. J. Janssen and P. Bäuerle, Org. Lett., 2009, 11, 4500-4503; (c) G. L. Schulz, M. Mastalerz, C.-Q. Ma, M. Wienk, R. A. J. Janssen and P. Bäuerle, Macromolecules, 2013, 46, 2141-2151; (d) F. Lincker, B. Heinrich, R. De Bettignies, P. Rannou, J. Pécaut, B. Grévin, A. Pron, B. Donnio and R. Demadrille, J. Mater. Chem., 2011, 21, 5238-5247; (e) W. W. Wong, C.-Q. Ma, W. Pisula, A. Mavrinskiy, X. Feng, H. Seyler, D. J. Jones, K. Müllen, P. Bäuerle and A. B. Holmes, Chem.-Eur. J., 2011, 17, 5549-5560; $(f)$ W. W. H. Wong, C.-Q. Ma, W. Pisula, C. Yan, X. Feng, D. J. Jones, K. Müllen, R. A. J. Janssen, P. Bäuerle and A. B. Holmes, Chem. Mater., 2010, 22, 457-466; (g) W.-S. Zhang, Dissertation, University of Ulm, 2014; (h) W. Zhang, G. M. Ng, H. L. Tam, M. S. Wong and F. Zhu, J. Polym. Sci., Part A: Polym. Chem., 2011, 49, 1865-1873; (i) B. L. Rupert, W. J. Mitchell, A. J. Ferguson, M. E. Köse, W. L. Rance, G. Rumbles, D. S. Ginley, S. E. Shaheen and N. Kopidakis, J. Mater. Chem., 2009, 19, 5311-5324.

23 (a) S. Deng, S. Sriwichai, P. Taranekar, G. Krueger, J. W. Mays and R. C. Advincula, Chem. Commun., 2011, 47, 8805-8807; (b) J. Zhang, M. K. Fischer, P. Bauerle and T. Goodson, J. Phys. Chem. B, 2013, 117, 4204-4215; (c) W. Kylberg, Y. Zhang, A. Aebersold, F. A. d. Castro, T. Geiger, J. Heier, S. Kuster, C.-Q. Ma, P. Bäuerle, F. Nüesch, J.-N. Tisserant and R. Hany, Org. Electron., 2012, 13, 1204-1212; (d) Y. Suda, R. Nishiyabu and Y. Kubo, Tetrahedron, 2015, 71, 4174-4182; (e) R. Satapathy, M. Ramesh, H. Padhy, I. H. Chiang, C.-W. Chu, K.-H. Wei and H.-C. Lin, Polym. Chem., 2014, 5, 5423-5435; (f) M. Tomassetti, F. Ouhib, I. Cardinaletti, P. Verstappen, A. Salleo, C. Jérôme, J. Manca, W. Maes and C. Detrembleur, RSC Adv., 2015, 5, 85460-85469.

24 S. Schmid, A. Mishra, M. Wunderlin and P. Bäuerle, Org. Biomol. Chem., 2013, 11, 5656-5665.
25 (a) M. K. R. Fischer, I. López-Duarte, M. M. Wienk, M. V. Martínez-Díaz, R. A. J. Janssen, P. Bäuerle and T. Torres, J. Am. Chem. Soc., 2009, 131, 8669-8676; (b) M. K. R. Fischer, T. E. Kaiser, F. Würthner and P. Bäuerle, J. Mater. Chem., 2009, 19, 1129-1141; (c) M. K. R. Fischer, C.-Q. Ma, R. A. J. Janssen, T. Debaerdemaeker and P. Bäuerle, J. Mater. Chem., 2009, 19, 4784-4795; (d) A. Mishra, E. Mena-Osteritz and P. Bäuerle, Beilstein J. Org. Chem., 2013, 9, 866-876.

26 C.-Q. Ma, W. Pisula, C. Weber, X. L. Feng, K. Müllen and P. Bäuerle, Chem.-Eur. J., 2011, 17, 1507-1518.

27 D. M. Stoltzfus, C.-Q. Ma, R. C. R. Nagiri, A. J. Clulow, P. Bäuerle, P. L. Burn, I. R. Gentle and P. Meredith, Appl. Phys. Lett., 2016, 109, 103302.

28 (a) O. O. Adegoke, M. Ince, A. Mishra, A. Green, O. Varnavski, M. V. Martínez-Díaz, P. Bäuerle, T. Torres and T. Goodson, J. Phys. Chem. C, 2013, 117, 20912-20918; (b) S. Deng, G. Krueger, P. Taranekar, S. Sriwichai, R. Zong, R. P. Thummel and R. C. Advincula, Chem. Mater., 2011, 23, 3302-3311.

29 J. Du, M. C. Biewer and M. C. Stefan, J. Mater. Chem. A, 2016, 4, 15771-15787.

30 (a) B. A. D. Neto, A. A. M. Lapis, E. N. da Silva Júnior and J. Dupont, Eur. J. Org. Chem., 2013, 228-255; (b) J. W. Jung and W. H. Jo, Chem. Mater., 2015, 27, 6038-6043.

31 (a) Y. Liu, J. Zhao, Z. Li, C. Mu, W. Ma, H. Hu, K. Jiang, H. Lin, H. Ade and H. Yan, Nat. Commun., 2014, 5, 5293; (b) J. Subbiah, B. Purushothaman, M. Chen, T. Qin, M. Gao, D. Vak, F. H. Scholes, X. Chen, S. E. Watkins, G. J. Wilson, A. B. Holmes, W. W. Wong and D. J. Jones, Adv. Mater., 2015, 27, 702-705.

32 (a) J.-L. Wang, Q.-R. Yin, J.-S. Miao, Z. Wu, Z.-F. Chang, Y. Cao, R.-B. Zhang, J.-Y. Wang, H.-B. Wu and Y. Cao, Adv. Funct. Mater., 2015, 25, 3514-3523; (b) L. Yuan, Y. Zhao, J. Zhang, Y. Zhang, L. Zhu, K. Lu, W. Yan and Z. Wei, Adv. Mater., 2015, 27, 4229-4233.

33 W. L. F. Armarego and C. L. L. Chai, Purification of Laboratory Chemical, Butterworth-Heinemann, Oxford, 7th edn, 2013.

34 C.-Q. Ma, E. Mena-Osteritz, M. Wunderlin, G. Schulz and P. Bäuerle, Chem.-Eur. J., 2012, 18, 12880-12901.

35 T. Johansson, W. Mammo, M. Svensson, M. R. Andersson and O. Inganäs, J. Mater. Chem., 2003, 13, 1316-1323.

36 J. Wu, Y. Ma, N. Wu, Y. Lin, J. Lin, L. Wang and C.-Q. Ma, Org. Electron., 2015, 23, 28-38.

37 M. Shao, J. K. Keum, R. Kumar, J. Chen, J. F. Browning, S. Das, W. Chen, J. Hou, C. Do, K. C. Littrell, A. Rondinone, D. B. Geohegan, B. G. Sumpter and K. Xiao, Adv. Funct. Mater., 2014, 24, 6647-6657. 